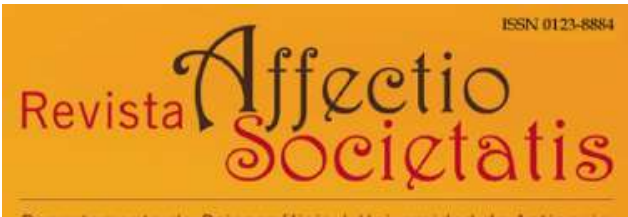

Departamento de Psicoanálisis | Universidad de Antioquia

Revista Affectio Societatis

Departamento de Psicoanálisis

Universidad de Antioquia

revistaaffectiosocietatis@udea.edu.co

ISSN (versión electrónica): 0123-8884

Colombia

2019

Diego Fernando Bolaños \& Marcelo Ricardo Pereira

RE-NACIMIENTOS Y BAUTISMOS EN EL RAP: MISTICISMO $Y$ RELIGIOSIDAD REPRESENTADOS EN SEUDÓNIMOS DE ADOLESCENTES

Revista Affectio Societatis, Vol. 16, № 30, enero-junio de 2019

Art. \# 2 (pp. 39-62)

Departamento de Psicoanálisis, Universidad de Antioquia Medellín, Colombia 


\title{
RE-NACIMIENTOS Y BAUTISMOS \\ EN EL RAP: MISTICISMO Y RELIGIOSIDAD REPRESENTADOS EN SEUDÓNIMOS DE ADOLESCENTES
}

\author{
Diego Fernando Bolaños ${ }^{1}$ \\ Universidad Federal de Minas Gerais, Brasil \\ diferbol 21@ hotmail.com \\ ORCID: 0000-0002-6629-4705 \\ Marcelo Ricardo Pereira ${ }^{2}$ \\ Universidad Federal de Minas Gerais, Brasil \\ marcelorip@ hotmail.com \\ ORCID: 0000-0002-0977-9124
}

DOI: 10.17533/udea.affs.v16n30a02

\section{Resumen}

Sintetizamos hallazgos de una investigación de contraste realizada en Colombia y Argentina. El método empleado fue de intervención clínica aplicada a la investigación utilizando espacios de habla, entrevistas de orientación clínica, diarios de bordo y clínico con los cuales conseguimos obtener discursos singulares de adolescentes y extrajimos salidas de constitución subjetiva. También usamos técnicas más convencionales con las que accedimos a discursos particulares que se tienen sobre adolescentes. Así conseguimos identificar, en adolescentes, raperos

1 Estadiario postdoctoral del programa de post-graduación en Conocimiento e Inclusión Social de la Facultad de Educación de la Universidad Federal de Minas Gerais (Brasil). Docente de Centro Federal de Educación Tecnológica de Minas Gerais CEFET-MG (Brasil).

2 Profesor de Psicología, Psicoanálisis y Educación del Programa de Posgrado y de la Facultad de Educación de la Universidad Federal de Minas Gerais (Brasil). 
y grafiteros, que sus salidas a la encrucijada de la adolescencia, relacionadas con las agrupaciones, se dan con la sustitución de sus nombres. Presentamos dos casos de raperos que con sus seudónimos buscan el fortalecimiento del lazo filial -social, en especial con las madres-.

Palabras clave: nominación, identificación, nombre propio, sustitución, par-cero.

\section{RE-BIRTHS AND BAPTISMS IN RAP: MYSTICISM AND RELIGIOUSNESS REPRESENTED IN THE ADOLESCENTS' PSEUDONYMS}

\section{Abstract}

We summarize the findings of a contrast research carried out in Colombia and Argentina. The method used was the clinic intervention applied to research by using talking spaces, interviews of clinic orientation, logbooks, and the clinic with which we could obtain both singular discourses of the adolescents and solutions of subjective constitution. We also used some more conventional techniques with which we had access to existing particular discourses on adolescents.
Therefore, we could identify that, among adolescents, rappers, and graffiti artists, their solutions -related to groups- to the adolescence crossroads happen by substituting their names. We present the cases of two rappers who seek, through their pseudonym, the strengthening of the filial-social bond, especially with their mothers.

Keywords: naming, identification, proper name, substitution, par-cero [buddy/pair-zero].

\section{RE-NAISSANCES ET BAPTÊMES DANS LE RAP : MYSTICISME ET RELIGIOSITÉ REPRÉSENTÉS PAR DES PSEUDONYMES D'ADOLESCENTS}

\section{Résumé}

Cet article présente de manière synthétisée des résultats d'une recherche contrastive effectuée en Colombie et en Argentine. La méthode employée 
a été celle de l'intervention clinique appliquée à la recherche. Des espaces de prise de parole, des entretiens à orientation clinique et des journaux cliniques et de bord ont permis l'identification de discours singuliers d'adolescents, ainsi que des processus de construction subjective. Des techniques plus conventionnelles ont également dévoilé des discours particuliers sur les adolescents. De cette façon, l'on a pu constater que chez les adolescents, rappeurs et graffiteurs, la substitution de leurs noms au sein des groupes représente le moyen de sortir du carrefour de l'adolescence. L'article présente deux cas de rappeurs qui, à travers leurs pseudonymes, cherchent à renforcer le lien filial-social, en particulier avec les mères.

Mot-clés : nomination, identification, nom propre, substitution, par-cero [pote/pair-zéro]. 


\section{Introducción}

Con el objetivo de encontrar evidencias sobre cómo se dan procesos de constitución de subjetividad en adolescentes que integran agrupaciones juveniles de ciudad (AJC), cómo dichas agrupaciones inciden en esos procesos y cómo se las arreglan esos adolescentes para resolver sus dilemas, realizamos una investigación-intervención ${ }^{3}$ de orientación clínica (Pereira, 2016; Bolaños 2017) en dos ciudades, una en Argentina y otra en Colombia, durante los años 2013-2016. En un primer momento de la investigación fue necesario levantar un estado del arte sobre la evolución conceptual y las concepciones históricas que sobre AJC y adolescentes se habían presentado desde que el concepto de adolescencia fue acuñado por Stanley Hall en 1904 (Matheus, 2007, p.33) y desde que las formas de agrupación juvenil se ubicaron como objetos de estudio en los primeros años del siglo xx. ${ }^{4}$ Seguido, nos sumergimos en trabajos de campo para obtener percepciones y concepciones que sobre adolescentes se presentan en las ciudades del estudio.

En dicha inmersión conseguimos obtener lo que identificamos como discursos particulares sobre adolescentes y que, básicamente, son las concepciones que tienen educadores, psicólogos, médicos, trabajadores sociales y personas adultas del común sobre jóvenes y adolescentes, haciendo énfasis en los adjetivos asignados y en los escenarios de actuación (Bolaños, 2017) que les adjudican en las ciudades. En líneas generales, los adolescentes son percibidos y clasificados como soñadores, rumberos, consumistas, rebeldes, solitarios, acelerados, apáticos políticos, vulnerados, entre otros. Algunos escenarios de ac-

3 La investigación intervención o pesquisa intervención es una metodología desarrollada ampliamente en Brasil en áreas de la salud y la educación y, en los últimos años, se ha implementado en estudios desde y con el psicoanálisis; de ahí que reciba la denominación ampliada de "orientación clínica", ya que en ella los principios psicoanalíticos de inconsciente, demanda, deseo, pulsión, síntoma (Pereira, 2012; 2016), entre otros, han posibilitado mayor alcance a este tipo de estudios.

4 Tarea académico científica inaugurada por la Escuela de Chicago después de la Primera Guerra Mundial, en los inicios, según Hannerz (1982), de la reconocida Antropología social. 
tuación que les asignan son el deporte, la educación, el baile, el consumo y el uso de alucinógenos. Nos llamó la atención que las AJC no fueron mencionadas como escenarios de actuación y tampoco las formas de vida de dichas agrupaciones se mencionaron como característica del actuar adolescente. También observamos que profesionales de la ciudad colombiana ubicaron a los adolescentes en escenarios de violencia social y estructural "(...) nuestros muchachos son vulnerados por el Estado" (Psicóloga 1); "(...) la generación de ahora sólo piensa en la rumba y no se preocupan por más (...)" (Adulto mayor de un grupo de gimnasia); mientras que en la ciudad argentina los profesionales no ubicaron a los adolescentes tan siquiera como víctimas de violencias.

Ya al obtener los discursos singulares (de los adolescentes), nos llamó la atención que, inversamente a como se les percibe, los sujetos que participaron en esa etapa del estudio sienten las agrupaciones como un gran escenario de actuación y protagonismo de sus propias vidas. Sobre las violencias, los adolescentes de Colombia no las mencionaron y los de Argentina hicieron explícita su posible participación en actos de violencia; incluso algunos, siendo víctimas, afirmaron que el Hip-Hop les ayuda a prevenirla. La obtención de los discursos singulares ${ }^{5}$ y su interpretación nos orientó hacia la denominación de par-ceros ${ }^{6}$; denominación que guarda consistencia con el principio de singularidad que rige al psicoanálisis.

5 Sobre los discursos singulares, asimilamos los planteamientos de Gallo y Ramírez (2012) al afirmar que: “Lo singular requiere que el investigador esté dispuesto a mantener abierto el abordaje metódico de lo imprevisto y de lo real no codificado" (p.95).

6 Término que significa compañero, colega, amigo y hermano, y que se ha expandido en su uso en Colombia, en especial en la región urbana de Antioquía y del Eje cafetero. Se popularizó en los años 80 , cuando novelas y películas costumbristas comenzaron a mostrar la vida citadina de jóvenes atravesada por las violencias, la delincuencia y el consumo de alucinógenos. La intención en esta investigación de escribirlo separado por un guion (par-cero), tiene connotación epistemológica de remitir a la singularidad desde la cual es imposible, a pesar de las similitudes, la igualdad. Así, no hay en los procesos de constitución de subjetividad sujetos que sean iguales y conformen pares; hay sólo unicidades, de ahí el par-cero o cero par. 
Finalmente, al entrar más en detalle en los discursos de los parceros, en especial en la búsqueda de rastros sobre la constitución de su subjetividad y la función de las AJC en ello, conseguimos identificar que, entre otras prácticas, el desplazamiento o sustitución de los nombres propios ${ }^{7}$ con apodos o seudónimos es una estrategia de construcción de lazo social y de identificación, no sólo con la agrupación, sino hacia afuera, a través de la obtención de reconocimiento, en especial con los seudónimos que en dos casos observamos como posibilidades de fortalecimiento del lazo fraterno-materno.

\section{Discursos singulares y/o sin lugares de los adolescentes}

Los adolescentes objeto de este estudio, en su mayoría pertenecen a las denominadas familias recompuestas (Roudinesco, 2003), en las que la existencia de hermanos puede darse por parte de ambos padres; los de Argentina, en caso de separación alternan la convivencia con los dos progenitores, los de Colombia quedan con las madres. Tal vez por ello dicha figura, la de la madre, es más referida y posicionada preferencialmente por estos adolescentes; mientras que en los de Argentina es blanco de críticas y de irrespeto.

En relación con su vida en las agrupaciones, estos adolescentes alternan dichas prácticas con jornadas de trabajo (algunos están inmersos en el mercado laboral, aunque de manera informal). Esas mismas prácticas son sustentadas con recursos obtenidos de su trabajo o de algún auxilio familiar; con lo cual podemos decir que no se ubican en estilos de vida consumistas en la lógica de las modas masificadas. Los adolescentes piensan sobre las instituciones escolares que son algo inútil, que "mecanizan a las personas" y no les permiten "desarrollarse creativa y críticamente", ya que los profesores son sólo "agentes repetidores de órdenes del sistema". Contrariamente observan las AJC como

7 Tanto los seudónimos como los nombres que se mencionan aquí han sido modificados para efectos de proteger la identidad de los adolescentes, según acuerdo establecido con ellos y principio ético formulado mediante el compromiso informado presentado y firmado al inicio del estudio. 
espacios que les posibilitan "ser libres y crear", aunque lamentan que muchos de ellos no puedan realizar sus prácticas en las instituciones.

De otro lado encontramos que, al hablar de su consumo de marihuana y alcohol, así como de ciertas prácticas de calle, algunos las asocian con su ingreso a las AJC y a la vida grupal en general. Otros aducen que la llegada a las AJC es una consecuencia de sus búsquedas, y que cuando llegaron a las agrupaciones ya habían experimentado o consumían dichas sustancias y andaban en las calles buscando “¿no sabes qué?" (Rapero 8).

De lo anterior observamos que estos adolescentes están "resolviendo" a su manera, además de sus "dramas" y "tragedias", advenidas muchas como consecuencia de la pubertad, el entramado de imaginarios y discursos que sobre ellos se han levantado. Tal vez por sus resoluciones es que desde el "mundo adulto" se elaboran juicios, como los escuchados en Cali y Mar del Plata, que les identifican como rebeldes, solitarios, consumidores, acelerados, soñadores, alegres, apáticos políticos, entre otras; así, pareciera que la calle, el baile, la rumba, el consumo, el trabajo, el deporte, las celebraciones, la irre-

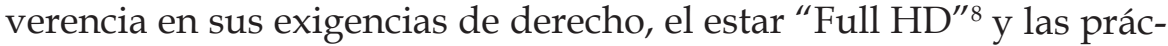
ticas sexuales abiertas, que fueron relacionadas como escenarios de actuación adolescente, llegan a funcionar como espacios de fuga y distensión en medio del trabajo psíquico que requieren realizar para llegar a tales resoluciones.

También observamos que estar en la calle y en el Hip-Hop son reportadas como el resultado de no encontrar contención en las familias y en la educación para poder responder a ese trabajo psíquico. Entonces, pareciera que el papel de las AJC puede sintetizarse en que en ellas el adolescente, al hallarse en la calle de frente a desafíos y viéndose en lo insoportable de su existencia, sienten que el otro, el par-cero que le lleva algo de ventaja en la vida con otras experiencias,

8 Estar "Full HD" se refiere a un estado de alegría, felicidad, placer y goce momentáneo alcanzado gracias a diversos elementos asociados al consumo, como lo refiere la canción "Ras tas-tas" del grupo Cali Flow, disponible en: https:/ / www.google.com.br/search?q=ras+tas+tas+cali+flow 
y el grupo, le secundan y apoyan, le dan contención, escucha y soporte. Es probable que ahí radique uno de los valores de estas agrupaciones para la constitución de esos sujetos.

Para sustentar las anteriores afirmaciones, nos detuvimos en una categoría emergente que surgió en el segundo momento de categorización de nuestro estudio: el nombre propio y, en especial, en cómo es puesto en "jaque" el universo simbólico y su campo de significados al sustituirlo por un sobrenombre, apodo o un seudónimo, y lo que ello puede significar en la constitución de la subjetividad. Entonces analizamos e interpretamos, desde la teoría psicoanalítica, algunos aspectos de las sustituciones de sus nombres y la relación con la constitución de su subjetividad.

\section{La sustitución del nombre propio con apodos en "par-ceros" agrupados: una opción de constitución de la subjetividad}

Antes de hablar de la sustitución de los nombres de los par-ceros, debemos hacer referencia a lo que comprende el nombre propio en psicoanálisis, foco central de nuestras argumentaciones. Inicialmente debemos afirmar que al tratar la temática del nombre propio en psicoanálisis, y de su complemento, la función del nombre, dos elementos emergen para la discusión. El primero es referente “(...) a la imposibilidad de la identidad ${ }^{9}$ como signo completo y cerrado, lo que abre el juego a las identificaciones" (Zelis, 2012, p. 777), tema en el cual el psicoanálisis ha dedicado basta producción desde Freud hasta la actualidad.

El segundo refiere al individuo y a la individualidad, definidos “(...) a partir de su unidad integrada(...) (que) se mantiene en la dialéctica adaptación-desadaptación" (Gallo y Ramírez, 2012, p. 256), frente a los cuales se posicionan los conceptos de sujeto y subjetividad, sus-

9 El mismo Zelis plantea que para el psicoanálisis, "hay identificación para el sujeto a causa de que no hay identidad" (2012, p. 777). 
ceptibles de transformación "mediante las variaciones simbólicas de sentido", ( p. 256) lo que marca una gran diferencia entre el psicoanálisis y la sociología, por ejemplo. Así, frente a estos dos elementos, se hace necesario decir que el uso/desuso del nombre propio no es cuestión de puesta en riesgo de la identidad y la individualidad, así como tampoco se trata de ponerse o quitarse una máscara, un vestido o un ropaje, aunque el nombre pueda ser asumido como algo que cubre al sujeto; pero, ¿qué cubre? sus deseos, a la vez que encubrió o sublimó los deseos de los progenitores, ya que nombrar es sublimar, hacer obra de la letra, facilitarse un pasaje en una vía obstruida; esto se aplica tanto a adultos que asignan nombres a los niños, como al adolescente que se asigna un apodo o que responde a un sobrenombre, incluso hasta al que se asigna un seudónimo.

La apropiación y uso del nombre propio involucran un trabajo de elaboración y duelo que implica, en términos de desprendimiento, dejar de estar identificado a los sentidos del Otro (Rivadero, 2011); es un acto de alta complejidad esta apropiación, luego, dejar de usar el nombre o una parte de él, implica un acto de también gran complejidad y no admite regularidad ni categorías. Es decir, sobre ello deberá hablarse desde las singularidades de los discursos y del sentido de quien se "des-nombra".

Con el nombre propio, el sujeto establece una relación que podemos calificar de significado del significante, ese que Zaiczik (2004, p. 3), llama "objeto recursivo" y que define como "una parte del objeto que guarda la información del todo". Con ello, el nombre propio sería una representación que se hacen del sujeto otros significantes, como nos lo hizo entender Lacan en Subversión del sujeto y dialéctica del deseo en el inconsciente freudiano (2009/1960, pp. 755-787). Es decir, el nombre propio funciona como un operador del sujeto que, al ser enunciado, entra a tener significación entre los demás.

Reconocemos que el nombre propio es ese significante que direcciona a ciertas marcas, pero es bueno aclarar que "(...) ningún conjunto de marcas concretas puede agotar el significado del nombre propio, a lo sumo, la marca esencial del sujeto sería, si fuera posible ceñirla, la continuidad de su historia" (Zelis, 2012, p. 780). Continuidad histó- 
rica del sujeto nombrado que no es ni la etimología del nombre, ni la forma específica de su asignación, ni cómo el sujeto se fue apropiando de él. De ahí que sea posible afirmar que el nombre propio con-trae en sí dudas, vacíos de existencia, huecos, espacios que profundizan la condición del sujeto incompleto. El sujeto de la falta, como lo estableció Lacan, así como el sujeto de las unicidades o de relaciones binarias elevadas a trascendencia de constitución subjetiva, como lo refirió Freud.

Una de esas unicidades es sujeto/significante. Es ahí donde vemos la trascendencia de la función del nombre: en la vinculación de un sujeto con su significante nominador y definidor que lo denota y lo connota en la medida en que lo interviene real, simbólica e imaginariamente. Lacan en el Seminario 9 (1961-1962) refirió del nombre propio un carácter demostrativo, esto es, que da descripciones abreviadas y que designa aspectos particulares de las cosas con lo cual se singulariza como un significante puro que acompaña al sujeto a todas partes; eso sí, con las características de ser intraducible y no interpretable, ya que lo que es susceptible de interpretarse es el conjunto de actos del sujeto del nombre. Los aspectos particulares de las cosas y singulares de los sujetos vienen a ser los rasgos especiales que contraen la(s) diferencia(s).

Pero, que guarde amplia relación con la identificación no es que sea la identificación total del sujeto (aunque con él se lo identifique), ya que no es de su propiedad (le perteneció al lenguaje de los otros) y fue elegido por los otros. Es decir, la elección de un nombre y su asignación traen un sentido, un deseo, un goce y un enigma que se escapa a quien lo detenta ahora, quedando ese sujeto en un vacío. Así, el nombre propio no es en sí tan propio, y más bien ha sufrido un proceso de apropiación gracias al cual los demás sujetos le asignan función de "identificador".

Podemos decir que el nombre se instaura en el inconsciente con función en lo que Lacan denominó registros real, simbólico e imaginario (1974-1975) que son, en palabras de Miller "los verdaderos nombres del padre" (Lacan, 2005, p.8). Así, como es referido en psicoanálisis, el Nombre del Padre se erige como ese significante que en 
la estructura de las significaciones viene a nombrar la falta en el Otro gracias a una afirmación primordial (Bejahung) en el sujeto, el deseo de la madre sobre él. Entonces, el nombre viene a constituir una marca, "(...) aplicada sobre el objeto, superpuesta a él" (Zaiczik, 2004). Marca superpuesta porque en la acción de nombrar y de nombrarse, el objeto del nombre es el sujeto nombrado, quien, a la vez, al ser nombrado convierte en objeto a ese otro que le nombra.

Todo ello se da a partir de la palabra dada que, como la refirió Lacan, “(...) es igualmente una forma de acto" (2005, p. 31). Así nombrar vendría a ser un acto enmarcado en lo simbólico, que transforma en objeto, cuasi palpable, aquello inaprensible, el sujeto/objeto que, aunque no esté, al ser evocado se trae a escena. El nombre propio, como palabra dada, como concepto, mantiene en el tiempo la imagen de un sujeto que se lo ha apropiado. Miller lo presenta así: “El nombre ya eterniza el sujeto, pero no su cuerpo" (1997, p. 92). Entonces, el nombre se ubica en el campo de lo simbólico universal e inmortal; concepto al que cada sujeto intenta igualar o alcanzar para asirlo a su cuerpo. Miller adiciona: “(...) habrá un momento en que el nombre permanecerá solito y ningún cuerpo vendrá a responder a la invocación" (p. 92). De esa forma el nombre y la función del nombre posibilitan la articulación entre lo real y lo simbólico. Dependerá de la apropiación, que cumpla la función de "hacer estar ahí" y de "hacer ser el que es" al objeto nombrado.

Ahora, el sentido del nombre, si es que lo tiene para el sujeto, más allá de su apropiación que le hace decir "mi nombre es", sólo puede sostenerse desde el registro de lo imaginario. Rivadero (2011, s.p.) en el blog Imago Agenda lo presenta de esta forma: “El nombre propio, si opera como tal, es una nominación válida a nivel del anudamiento de lo Imaginario a los demás registros". Entonces, sostén y sentido emergen como elementos de importancia para el nombre. En relación al soporte del sentido en lo imaginario, Lacan afirmó: "El sentido, es aquello por lo cual responde algo que es diferente que lo Simbólico; y este algo no hay medio de soportarlo de otro modo que por lo Imaginario" (1974-1975, p. 4). Dicha labor de soporte o sostén se encuentra en la lógica de ver que el efecto de sentido, en nuestro caso del nombre, sólo es posible mirarlo en términos de lo "'intelligere', leer entre líneas a 
saber en otra parte que la manera en que lo simbólico se escribe" (p. 4); es decir, leerlo en la lógica de lo que ese nombre y su apropiación han significado para el sujeto que lo detenta, y no en la condición del signo (etimología o historia del nombre testimoniadas por terceros). Pero esa lógica sólo puede leerse a partir del discurso del sujeto nombrado.

Entonces, el nombre propio supera la condición de identidad social y se ubica en la función de re-presentante histórico del sujeto. Con todo y eso, dos premisas irrumpen sobre la función del nombre: 1. Instaura la sujeción del sujeto a su cultura desde el deseo de los Otros que lo han nombrado y, con ello, incluido en ese universo llamado lenguaje, desde donde se sostiene para interpretar su mundo; 2. En su apropiación es usado por el sujeto, desde su "propio" deseo, para nombrarse y representarse ante el deseo de los otros. Bajo esas premisas podemos deducir otro inter-juego articulador del nombre propio, y es el que promueve entre el registro simbólico y el imaginario. Dicho inter-juego lo podemos operar así: al recibir un (su) nombre el sujeto recibe, además de un concepto, la posibilidad de acceder a un universo simbólico regulado por el lenguaje. Al entrar usa su nombre para presentarse y representarse ante los otros; para ponerlo y ponerse él en el juego social.

Finalmente, en correspondencia con los registros mencionados, nos es posible hablar de tres (3) dimensiones del nombre propio y de su función (función del nombre): Real, Simbólica e Imaginaria, que operamos en la siguiente descripción. En el registro de lo Real se relacionarían con el otro ante el cual se da el nombre y que opera la nominación (nombra). En el registro Imaginario implicarían el sentido que el sujeto les otorgue en relación a como ha sido nombrado. En el registro de lo Simbólico, nombre y función del nombre se moverían en el deseo, "eterno", de ser nombrado, de ser llamado por el otro. Podemos afirmar, como lo estableció Lacan, que como los efectos de los tres (3) registros por sus anudamientos, también el nombre propio y función del nombre presentan "efecto de sentido, efecto de goce y efecto [...] de relación" (1974-1975); pero que solo existen nombre propio y función del nombre si el primero ha revestido un sentido para el sujeto, es decir, que sólo en el registro de lo Imaginario nos es posible ubicar su verdadera existencia, con la cual, en el acto nominador, a su vez, el sujeto adviene a existir. 
En el trayecto de nuestra investigación algunos par-ceros se presentaron con apodos, posibles máscaras sostenidas desde sus imaginarios; ante ello nos asaltaron interrogantes: ¿qué encubren o qué rechazan?, ¿qué desean generar?, ¿tal vez una nueva condición bautismal?, ¿será, entonces, que se asumen en un nuevo nacimiento?, ¿qué quieren representar-se?, ¿quizás un rechazo al mundo simbólico desde el que fueron nombrados?

Entonces, como el nombre puede ubicarse en la lógica de ser el representante histórico del sujeto o de conferirle una identidad, como lo afirma Roudinesco (2003), y siendo uno de los primeros se convierte, como lo da a entender De Lajonquière (1992), en significante por excelencia del sujeto. El nombre, haciendo parte de ese gran universo simbólico llamado lenguaje, es usado por el sujeto para, además de presentarse, manifestar al Otro su deseo de ser llamado; con ello se ubica como base para la identificación, el auto-reconocimiento y el reconocimiento de la otredad que le nombra, y más en la condición adolescente $^{10}$. En ese sentido, sustituirlo, reemplazarlo o desplazarlo con un apodo, sobrenombre o seudónimo, es un fenómeno para ser analizado debido a las implicaciones que con-trae para la identificación, y con ello para la constitución de la subjetividad.

Podemos afirmar que al sustituir el nombre, práctica muy frecuente en la adolescencia ${ }^{11}$, no importa la razón que lo oriente, el sujeto se enfrenta a una doble identificación o, en su defecto, a dos "nominaciones latentes", la del primer nombre y la de su sustituto. Nominaciones que podemos asumir en la perspectiva de ser núcleo significante del inconsciente, como lo afirmó Lacan en el Seminario 9 (1961-1962, Clase 7) sobre el nombre propio: “(...) el primer núcleo, como significante

10 Desde nuestra perspectiva, la adolescencia no es una etapa ni un momento del desarrollo, la asumimos como condición, ante todo subjetiva y luego contextual, cultural, ideológica, entre otras; y adicionalmente como una(s) perspectiva(s) de vida de quien(es) presente(n) tal condición o está(n), como lo plantearon Aberastury y Knovel (1994), en ese proceso.

11 Práctica manifiesta con diminutivos, recorte de los nombres, siglas tomando parte del nombre y apellido, o toma de un sobrenombre de algún artista o deportista famoso. 
de lo que enseguida va a organizarle como cadena giratoria, tal como desde siempre se las he representado por ese centro, ese corazón hablante del sujeto que llamamos 'el inconsciente' (p. 35)".

Esas nominaciones latentes serán mediadas por el deseo (de cambio y de posesión) y sustentadas por la acción desde el registro de lo Imaginario, pues es desde dicho registro que el mismo sujeto orienta y soporta sus experiencias vitales y también su universo simbólico, atravesados ambos (experiencias de vida y universo simbólico) por trazos, rasgos o marcas que provienen del deseo de los otros que le han nombrado. Pero, al apodarse, darse un sobrenombre o asumir un seudónimo, hay un valor de placer, un lucro que esta acción deja. No podemos, entonces, analizarlo por fuera de tal ganancia en la economía psíquica, adicionándole que también le llega a significar inscripción "propia" a un mundo significante con sus marcas en la asignación, como sucede con lo que, por ejemplo en Brasil, se ha denominado nombre social ${ }^{12}$, con el cual un estudiante ya puede ser llamado en las instituciones educativas.

En unos adolescentes partícipes del estudio, la sustitución ha sido hecha en orientación artística, como seudónimo que encierra cierta tendencia de mercadeo con ese otro nombre. Tal orientación la encontramos, por ejemplo, en Tres, JoyJo y Mariamnna. En otros, la sustitución se condice con ciertas actitudes cotidianas del adolescente, es el caso de Tirador, Virus y Secreto. Y también observamos que en algunos el sonido o la referencia escrita del apodo fueron los referentes para realizar el remplazo, lo que se dio con Toscó, Isab y Pio.

12 La referencia es a la "portaría \#33" (Norma aprobada por el Consejo Nacional de Educación Brasilero en septiembre de 2017 y decretada el 17 de enero de 2018 por el Ministerio de Educación Nacional de Brasil), que reconoce legitimidad a los nombres asignados o tomados, en especial en las comunidades LGBT. Otros referentes importantes al respecto los encontramos en la Resolución No. 18 del 25 de abril de 2018 del Secretario de Estado de Seguridad Pública de Minas Gerais SESPN (También Brasil), donde se ordena, en líneas generales, que a los y las adolescentes en medidas socio-educativas se les registre en el Plan Individual de Atendimiento (PIA) con su nombre social. Similar determinación fue tomada por el Tribunal Superior Electoral TSE con el denominado Título de elector en todo el territorio brasilero. 
Tanto como seudónimo o como representación de sus actitudes, o en seguimiento a ciertas marcas sonoras y escritas, podemos decir que de lo que se trata es de un desplazamiento del nombre y con ello de una separación del proceso de apropiación y significación realizado. Sobre este desplazamiento nos parece importante la afirmación de Rivadero (2011, s.p.): “Separarse del nombre propio elegido por el Otro, bajo el sentido del otro, representa un enigma y un desafío para el sujeto". Desde otra lógica, Zelis aporta algo interesante sobre la sustitución al afirmar que: "Muchos 'nombres' y 'apodos' funcionan como nombres propios para evitar la angustia de la falta, y en los casos más difíciles para armar un 'sostén' imaginario ahí donde algo falló en la estructuración a partir de las identificaciones” (2012, p.780).

Tanto como desafío o como sostén es posible mirarlo, como lo hizo Freud (1985) en el caso del olvido del nombre propio Signorelli, con referencia al deseo de eliminar una situación reciente (en los adolescentes tal vez gran parte de la niñez). Es decir, con la sustitución, el nombre propio sería sometido a represión, lo cual facilitaría la emergencia de un sustituto; hay casos en que la sustitución elimina cualquier parecido del signo (etimología, deseo de los padres, etc.) haciendo emerger otro sentido constituido en el deseo, el deseo de ser llamado diferente. Esto para la auto-asignación de apodos. ${ }^{13}$

Pero es posible hallar también cierta conexión de contenido entre el nombre propio y el sustituto. Conexión que no corresponde al ámbito de lo consciente, incluso tratándose de una sigla, una abreviatura o un derivado del nombre. Así, concluiremos como lo hizo Freud en el referido caso, que no nos atrevemos a afirmar que todos los casos de sustitución se rijan bajo el mismo principio. Es posible que en algunos casos algo o todo el sentido advenido con el nombre propio se quiera reprimir; en otros es posible que algo de ese mismo sentido se quiera resaltar o sobreponer; en ambos (represión o sobre-

13 Para la asignación a otros de un apodo o llamar a otros por el sustituto, podríamos referir una supuesta potestad de ser "el bautista"; el Bautista, aquel que fue elegido para dar nombre a los otros, con lo cual se considera más que esos otros bautizados por él. Sin embargo, no es la orientación que nos interesó en la investigación, de ahí que sólo hagamos aquí esta pequeña referencia. 
posición) una constante emerge, la pluri-causalidad. Ahora teniendo como base lo planteado, vamos a los casos.

Ante la invitación para que se presentaran y hablaran de su experiencia en la agrupación, algunos de los par-ceros lo hicieron obviando el nombre y reemplazándolo con el apodo o seudónimo que les identifica en la AJC, incluso ampliando información acerca de cómo lo tomaron.

Yo soy, no voy a decir mi apodo; bah, si lo voy a decir; soy el Tirador... y se me ocurrió porque estaba viendo una propaganda, una de la red, de esa de 'speed', y una viejita estaba jugando al 'Country Stade' (risas) y llega y dice: "aguarda, atrás hay un tirador" (risas). Entonces, suachh, me sonó en la cabeza ahí y fui y corte... Tirador (risas).

Otros iniciaron haciendo referencia a su pertenencia a la agrupación: "soy artista Hip Hop" (JoyJo); "soy rapero, estudiante y compositor" (William Alberto); "Soy Virus, bah me dicen Virus (...) antes sólo hacía firmas mías, las miraba, ahora tengo mi seudónimo y ya (...)" (Simón).

Esto sucedió en las entrevistas y espacios de habla, orientándonos a atender aspectos del sentido de tal sustitución y las formas en que se veían implicadas sus identificaciones. Es decir, analizar esos reemplazos o desplazamientos de los nombres propios como actos que conllevan impacto identitario y, con ello, en la constitución de su subjetividad. Hubo dos casos de sustitución con seudónimos (Mariamnna y Tres) que, inicialmente, indicaron solo pretensión de los par-ceros de resaltar su condición artística, a la vez que iniciar o completar el desasimiento respecto de la autoridad fraterna; sin embargo, al mirar en detalle los discursos referidos a los procesos de sustitución, hallamos puntos de misticismo y elevación de la figura materna. Así, encontramos no un desligamiento, sino una religación, en especial a ese gran objeto deseado-amado iniciáticamente: la madre.

a. Mariamnna, cuyo nombre es Ana María, nos manifestó un gran amor hacia su madre, con quien vivió un tiempo. A ella le da lugar de "salvadora" por haberla sacado del consumo de drogas cumpliendo algo que ella misma refiere como un "designio de Dios": 
(...) mi mamá empezó a ir a la iglesia y ella oró por mí y me ayudó a salir, eso; me rescató de la droga... tuve un encuentro con Dios (...) Él, a través de mi mamá, me hizo salir de esa situación (...)

Analizamos este seudónimo como signo (con apoyo en la etimología) y como significante - en clave del discurso de Mariamnna - hallamos lo siguiente: Marian es un nombre hebreo derivado de María, la cual es "la elegida" o "la amada por Dios"; y Ana refiere compasión o que Dios se ha compadecido. Si es elegida, entonces está en gracia con Dios, a la vez que este se ha compadecido por ella, ella se siente a salvo. El estar a salvo o ser salvada, como efectivamente considera que lo fue al salir de las drogas. Pero el seudónimo Mariamnna es escrito con dos " $n$ ", al ser cuestionada por ello nos respondió: "significa nuevo nacimiento". Nuevo nacimiento que ubica en dos partes: la salida de las drogas y la pertenencia a una iglesia ("vivo una vida espiritual"), es decir, como significante de un nuevo ser.

La consistencia de este juego de significados la ubicamos en la lógica de que solo es posible vivir si se nace, y que un segundo nacimiento solo es posible si se ha muerto; tal parece que quien era anteriormente murió. Es decir, en ella se reproduce uno de los actos de mayor devoción en la fe cristiana: la resurrección. Ella ha resucitado, ella, entonces, tiene la gracia del Padre. Es, en cierta forma, la Mesías que habiendo sido salvada ahora es salvadora (Mariamnna nos refirió que sus canciones llevan mensajes para ayudar a la juventud al igual que asiste a un centro misionero Bethesdá). Así, nos parece que la renovación de su nombre se orienta en el fortalecimiento de su significante actual marcado por la fe cristiana y no tanto por la práctica del rap, o al menos en la forma como inició.

Pero en la escritura del apodo, además de la doble " $\mathrm{n}$ ", se intercepta la $\mathrm{m}$, que acentúa la pronunciación de la parte final, Anna, y con ello, tal vez, acentúa o fortalece su "estar en gracia", su salvación, y también su don mesiánico. También " $m$ " es la inicial de madre/mamá, quien materializó el milagro de su salvación de las drogas. Esta conjetura se nos ratifica al escuchar en 
una de sus canciones la narración del drama vivido por su progenitora cuando Mariamnna consumía drogas; una de las frases de obertura dice: "Gracias mamá por doblar tus rodillas y aferrarte a la promesa que Dios te dio". Es decir, Mariamnna posiciona, en su discurso artístico, el imaginario de un Dios que promete. ${ }^{14}$

Entonces, su representación en el seudónimo implica refrendar su condición de ser salvada, y una doble gracia (de ella y de la madre) que fortalece (acentúa) el vínculo con la progenitora revalidado en el sentir de un "nuevo nacimiento". Renacer teniendo como protagonista a la misma madre, algo que nos indica ese deseo de reforzar/renovar el vínculo con su progenitora, como Yahveh lo hizo con Moisés en la "alianza".

b. Tres, de nombre Octavio, nos argumentó que aquel, que califica como su "nombre artístico", lo tomó “(...) el 13 de enero de 2013, día que comienzo mi carrera musical"; asegura que pensó en su historia personal, en su familia, en su madre y “(...) fue cuando me puse a pensar sobre mi nacimiento que fue el 3 de marzo, dia 3 y mes 3, jejeje...", y que recordó aspectos familiares, religiosos y de proyección artística como:

(...) con mis hermanas me llevo 3 años de diferencia (...) 3 son las personas de la trinidad (...) 3 es como ese espiritu de revolución; nombre corto, de fácil recordación (...) que es ese espíritu de, de hacerle entender a la gente sobre las raíces que tenemos (...) psicológicamente en, pues, con, en los números, también tiene un significado agradable, ¡eh! también es usado creo que por él, por Alá y vainas así; pero pues lo veo más por la psicología, psicología de los números.

Al pedirle una auto-descripción desde su seudónimo refirió:

14 El Dios que promete es la representación de un acto que tiene inmenso valor en la Biblia, pues es, tal vez, uno de los trayectos de la fe cristiana de mayor muestra de milagros y de fuerza del Dios en cuanto a la protección del pueblo elegido liderado por Moisés. 
A Tres lo veo como una persona como independiente, llena de ideas, creativa. ¡Eh!, algo místico, tres personas distintas y un solo Dios, teorías mayas y la psicología del número, donde se refiere que es el signo de la expresión artística. No sé, ;tiene muchos significados el tres!; entonces me pareció muy, muy apto, pues, para mi proyecto. Igual no soy, pues hago rap, pero puedo mezclarlo con muchos otros ritmos, el punk, el jazz. No soy como tan purista dentro de la cultura. Trato de mantener la esencia, pero sí poderme nutrir de muchas cosas, y... yo creo que el tres lo representa; es como lo que más representa.

La referencia a la psicología del número, en la que da la impresión que este rapero se apoyó para, en algunos momentos, describirse como: “(...) persona independiente, llena de ideas, creativa (...)", puede ser una referencia a la grafología que, según el diccionario de la RAE, es "el arte que pretende averiguar, por las particularidades de la letra, cualidades psicológicas de quien la escribe". Se especula de la grafología que tiene un valor científico y permite "(...) descubrir, mediante el estudio de los números, el equilibrio entre los valores espirituales y materiales de las personas aplicando los mismos aspectos gráficos que a la letra escrita (orden, dimensión, claridad o legibilidad, dirección, inclinación cohesión)" ("Grafología, números y su significado psicológico", 2016); la misma es utilizada, incluso, en los procesos de selección de personal en empresas.

Tomamos esa referencia importante, aunque es a la escritura y no tanto al fonema, como parece ser el caso de Tres, que resalta de su seudónimo que "(...) es un nombre corto, de fácil recordación. Psicológicamente en, pues, con, en... los números también tiene un significado agrada$b l e^{\prime \prime}$. Adicionalmente, hubo una sentencia que nos llamó la atención al referir de su "nombre artístico" aspectos fuertes de identificación con las siguientes afirmaciones: "(...) Tres es mi significante directo y no simplemente otro nombre". Nos preguntamos, entonces, ¿qué es lo que quiere ser y qué le significa tal sustitución? Al buscar en sus narraciones encontramos una especie de desdoblamiento con un "uno" que atraviesa su discurso en los siguientes términos:

(...) generalmente, Tres es una persona distinta a lo que es Octavio. Octavio es más..., ha sido como educado de otra forma, de pronto de forma más sumisa, más tranquila, de una forma que encaje con la sociedad; pero Tres 
trata más como de sacar todo eso que realmente rechaza y que realmente no le gusta (...) cuando hago música, uno se olvida de los problemas, adquiere más que una fuerza física, adquiere una fuerza mental, espiritual que le permite a uno enfrentar los problemas y toda situación, porque tiene uno fortaleza, que por ejemplo hace que la gente se identifique (énfasis nuestro).

La presencia del "uno" nos sugirió la autoimagen de un entero, un "no dividido", a la vez de verse como un todo. Así interpretamos que Tres puede ser el que le habla de sí mismo y le completa, como el misterio de la trinidad: "tres personas distintas..." (es importante destacar, de igual forma, que en lo extenso del discurso, Tres fue recurrente refiriendo que sus logros son "gracias a Dios"). Al estar completo o completarle la disposición imaginaria de ese "uno", en relación con Tres, es el de una unidad con fuerza física, mental y espiritual (elementos que él menciona) y con el que imagina que la gente (los demás) le identifican. Mientras Tres se apoya en uno para complementarse, su nombre, Octavio, sería su antónimo, "una persona distinta", el "no uno", el significante dividido que siempre ha estado así; por lo cual, tal vez, no desea que aparezca porque ha sido educado de forma "sumisa".

Entendemos entonces que el Tres tiene aquí más función de renovación, cambio y hasta de eliminación de signos con-traídos con el nombre propio; tal vez una búsqueda inconsciente de sentirse un "uno", no dividido por otros y sí, más bien, que la gente lo vea unificado, entero. Recordemos que uno (1) sólo es divisible por él mismo y da como resultado 1 ; y 3 es divisible, además de por sí mismo, por 1, el universal divisor de todos que se mantiene como él mismo. De ahí otro elemento que se nos presentó, si su seudónimo podría funcionar como exteriorización de un deseo de anticipación en relación con su nacimiento, o de diferenciación extrema de sus dos hermanas, ya que tres, el número, es el segundo impar entero y sólo es divisible por uno y por él mismo.

Deducimos que tal vez sea eso lo que Tres desea; no estar a la par de sus hermanas, no dividir con ellas ¿el amor de la madre?; ser sólo divisible por el uno, el uno que tanto menciona y que es no dividido porque incluso puede estar en la referencia de ese deseo de la madre 
con quien vive solo y a quien da sostén económico, lo que no hacen sus hermanas, a pesar de todo el sacrificio que ella hizo para sacarlas adelante. Por eso es inconcebible que el amor de la madre esté divido con ellas, pues ellas no son gratas. Pero, a la vez intuimos que Tres le ofrece evitación de la angustia de la falta, aquella que se profundiza al sentirse dividido como Octavio. La falta hallada en Octavio, quien es 3 años menor que sus hermanas.

Ahora, en la idea de mostrar la conexión o ligazón que, pensamos existe, entre este seudónimo y la progenitora, tomaremos como base de análisis algunas de sus afirmaciones que develan, a nuestro juicio, tales relaciones. Cuando nos refiere que para llamarse Tres "me puse a pensar sobre mi nacimiento, que fue el 3 de marzo, dia 3 y mes 3". Al igual que con Mariamnna aparece el acto de nacer, y con él, de manera implícita, la existencia de la madre. Entonces hay una conexión que podemos deducir por temporalidad, el tiempo de haber nacido. Más aún, el día que lo toma es cuando inicia su carrera musical (13 de enero de 2013), que puede referirnos, también, a un nuevo nacimiento, en este caso el artístico; el Uno que renace como Tres.

Ampliando nuestra interpretación y análisis de la sustitución de nombres con los seudónimos Mariamnna y Tres, observamos que, además del fortalecimiento del significante de salvación y la evitación de la angustia, al estar enmarcados en ámbitos artístico-culturales, pueden ser la reinstalación (repetición) del deseo de agradar a las madres, de rendirles tributo y, en correspondencia, la imagen de una madre deseosa de ser agradada. Agrado que es dado por medios diferentes, pero de similar forma. Si para Tres tal agrado se presenta impulsado por el reproche hacia las hermanas y destaca que él ve por la madre, siendo menor que ellas; en Mariamnna se presenta con gratitud hacia la madre por haberla salvado de la droga y por su ingreso a la iglesia. Reproche y gratitud se presentan de forma mística y derivadas, pensamos, de ese marco monoteísta que, con su gran padre salvador y pasador de la Ley simbólica, tal vez tuvo representación en los actos iniciáticos de las madres y en sus figuras de mártires, mujeres sacrificadas y salvadoras que cumplieron, como misión, la crianza "solas". Pero, y ¿por qué esa forma?; ¿por qué decimos que buscan agradar a sus madres? Intentemos explicar. 
En la medida en que esos seudónimos se convierten en sus representantes como artistas ante otros significantes (artistas y público) obteniendo reconocimiento; en esa representación estaría dada la satisfacción a las madres deseosas de estar en "gracia" y de tener goce místico. Por eso se los asignan, los traen hacia sí, los apropian y luego los ofrecen a ellas mismas representadas por los públicos que escuchan sus canciones y que, al final, al aplaudirles les ofrendan. Estos raperos reciben los aplausos y los transfieren, simbólicamente, a esos seres deseosos de su gratitud generándose efectos de goce. Goce interpuesto en el goce de las madres, su goce es transmitido a sus madres para que ellas gocen.

Entonces, la sustitución de nombres en estos adolescentes nos permite hacer salvedad sobre el posible rompimiento con las generaciones adultas que el psicoanálisis y otras ciencias refieren como necesario para la evolución humana. Estos adolescentes, contrariamente, buscan mantener el goce de las madres a través de sus seudónimos, los cuales casi que representan ofrendas para ellas en la medida en que a través de ellos (los cuales en sus raíces tiene origen del relacionamiento con las madres y sus imaginarios sobre ellas como lo describimos arriba) obtienen reconocimiento artístico y son aplaudidos en los escenarios. Estos aplausos se convierten en prendas de gratitud hacia las progenitoras que, o les salvaron la vida o se han sacrificado por ellos.

Así, podemos decir que un significante amo proveniente de los discursos de las madres (y las madres mismas) se incrustó en los superyós de Tres y Mariamnna, convirtiéndose en taras de apego, lastres afectivos parentales y obstáculos subjetivos, quedando representado allí fuertemente el lazo con ellas. En devoción a la gratitud que deben guardar a sus madres por sus sacrificios y por ser sus salvadoras, ellos, inconscientemente, las marcan como trazos en sus seudónimos y con ello les rinden tributo, lo que se fortalece y remarca cada que se presentan como Tres o como Mariamnna.

\section{Consideraciones finales}

Resaltamos que las ideas y percepciones existentes sobre adolescentes y sus escenarios de actuación no corresponden con las realidades 
que ellos afrontan. Observamos que en sus estrategias para resolver la encrucijada de la adolescencia, los adolescentes usan los recursos que su condición psíquica les permite, entre ellos la sustitución de sus nombres. Conseguimos identificar, interpretar y analizar nueve (9) casos que nos dieron evidencia sobre tal proceso como factor de constitución de subjetividad. Hicimos el recorte de dos (2) casos de sustitución de nombre con seudónimos de dos raperos, y dedujimos que a estos adolescentes la sustitución les permite rendir tributos a sus madres y mantener, así, vivo sus lazos filiales, desde donde se erigen como salvados pero, a la vez, como protagonistas de su vida artística en el rap. La sustitución con seudónimo intervino directamente y revivió trazos de la identificación primaria de estos adolescentes, en la medida en que posibilitó una transferencia desde los trazos iniciales ligados con lo más universal que detenta el sujeto (el lenguaje a partir del nombre) hacia las relaciones horizontales, obteniendo de los otros, ubicados en este nivel, tributos a la imagen del representante del trazo iniciático: la madre.

\section{Referencias bibliográficas}

Aberastury, A., Knobel, M. (1994). La adolescencia normal. Un enfoque psicoanalítico. Buenos Aires, Argentina: Paidós.

Bolaños, D.F. (2017). Respiramos el mismo, pero somos diferentes. Constitución de subjetividad en Adolescentes que integran agrupaciones juveniles de ciudad en Cali (Colombia) y Mar del Plata (Argentina) (Tesis doctoral). Universidad Federal de Minas Gerais. Belo Horizonte, Brasil. Recuperada en: http:// www.bibliotecadigital.ufmg.br/dspace/handle/1843/BUOSAQRNGJ.

Brasil, Ministerio Nacional de Educación. Portaria No 33 de Janeiro 17 de 2018. Recuperado de: https://g1.globo.com/educacao/noticia/mechomologa-resolucao-que-permite-que-transexuais-e-travestis-usem-onome-social-nas-escolas-do-brasil.ghtml Con acceso 21/01/2018

De Lajonquière, L. (1992). De Piaget a Freud. Petrópolis, Brasil: Vozes. Real Academia Española[RAE]. (2016). Grafología.rae.es. Recuperado de: www.lema.rae.es/drae/?val=grafología.

Freud, S. (1985). Psicopatología de la vida cotidiana. Bogotá, Colombia: Círculo de Lectores. 
Gallo, H., y Ramírez, M. (2012). El psicoanálisis y la investigación en la universidad. Buenos Aires, Argentina: Grama.

Grafología: números y su significado psicológico (1 de febrero, 2016). Grafología y personalidad. Recuperado de: https://www.grafologiaypersonalidad.com/grafologia-numeros/.

Hannerz, U. (1982). Exploración de la ciudad. (Isabel Vericat y Paloma Villegas Ciudad (Trads.). México: Fondo de Cultura Económica. Recuperado en: http:/ / pt.scribd.com/doc/105945650/92967456-Hannerz-Los-Etnografos-de-chicago-en-La-Exploracion-de-La-Ciudad.

Lacan, J. (2009). Escritos 2. Buenos Aires, Argentina: Siglo Veintiuno Editores. Tercera edición revisada por Tomás Segovia, Juan David Nasio y Armando Suarez. (Original de 1966(

Lacan, J. (1961-1962). Seminario, Libro 9: La identificación. En Psikolibro. Recuperado en: http:/ / centrodedifusionyestudiospsicoanaliticos.files.wordpress.com/2013/03/20-seminario-9.pdf.

Lacan, J. (1974 -1975). Seminario RSI. En Psikolibro. Recuperado en: http:/ / centrodedifusionyestudiospsicoanaliticos.files.wordpress.com/2013/03/20seminario-22.pdf.

Lacan, J. (2005). Os nomes-do-pai. Telles, A. (Trad). Rio de Janeiro, Brasil: Jorge Zahar.

Matheus, T. (2007). Adolescência. São Paulo, Brasil: Casa do Psicólogo.

Miller, J. A. (1997). Lacan elucidado. Palestras no Brasil. Rio de Janeiro, Brasil: Jorge Zahar.

Pereira, M. (2012). A orientação clínica como questão de método à psicologia, psicanálise e educação. En: Pereira, M. R. (org.). A psicanálise escuta a educação: 10 anos depois (pp. 23-34). Belo Horizonte, Brasil: Fino traço.

Pereira, M. (2016). O nome atual do malestar docente. Belo Horizonte, Brasil: Fino traço.

Rivadero, S. (2011). El nombre propioy el propio nombre. Imago Agenda. Recuperado de: http:/ / www.imagoagenda.com/articulo.asp?idarticulo=1610.

Roudinesco, E. (2003). A família em desordem. Rio de Janeiro, Brasil: Zahar.

Zaiczik, C. (julio, 2004). Del ser al nombre propio. En: Jornadas Aniversario "30 años de Escuela (1974-2004)". Conferencia llevada a cabo en la Escuela Freudiana de Buenos Aires, Argentina.

Zelis, O. (2012). La función del nombre en psicoanálisis: articulación entre las concepciones de J. Lacan y C. S. Peirce. IV Congreso Internacional de Investigación y Práctica Profesional en Psicología; XIX Jornadas de Investigación; VIII Encuentro de Investigadores en Psicología del MERCOSUR (pp.777-781). Facultad de Psicología - Universidad de Buenos Aires, Buenos Aires, Argentina. 